\title{
Influence of Extraction Conditions on the Recovery of Phenolic Antioxidants from Spent Coffee Grounds
}

\author{
Antonio Zuorro and Roberto Lavecchia \\ Department of Chemical Engineering, Materials and Environment, \\ Faculty of Engineering, Sapienza University, Via Eudossiana 18, I-00184, Rome, Italy
}

Received 2013-05-01, Revised 2013-05-25; Accepted 2013-05-28

\begin{abstract}
The extraction of phenolic compounds from Spent Coffee Grounds (SCG), a waste produced in large amounts worldwide, was investigated. SCG were rich in fiber and protein and had a total phenolic content of $18.75 \pm 0.43 \mathrm{mg}$ GAE per gram dry weight. Extraction experiments were carried out in batch mode, using ethanol-water mixtures as solvent. A two-level factorial design was used to study the effects of temperature $\left(\mathrm{T}=20-60^{\circ} \mathrm{C}\right)$, extraction time $(\mathrm{E}=30-80 \mathrm{~min})$ and liquid-to-solid ratio $\left(\mathrm{R}=10-50 \mathrm{~mL} \mathrm{~g}^{-1}\right)$ on the recovery

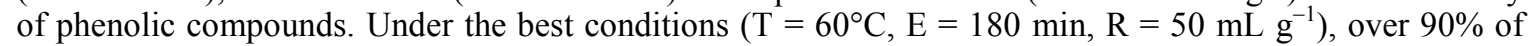
the phenolics present in SCG were recovered. T and R were the most influential factors and both had a positive effect on the extraction efficiency. The antioxidant activity of the extracts, determined by the DPPH method, was highly correlated with the amount of phenolics in each sample, suggesting that these compounds are the main responsible for the antioxidant properties of the extracts. Overall, the results of this study provide clear evidence of the potential of SCG as a source of natural antioxidants and give useful directions on how to improve their recovery by proper selection of extraction conditions.
\end{abstract}

Keywords: Spent Coffee Grounds, Extraction, Phenolic Compounds, Antioxidant Activity, Influential Factor Analysis

\section{INTRODUCTION}

According to data from the International Coffee Organization (ICO, 2012), about 100 million bags of coffee, corresponding to over 7 million tons of green coffee beans, are produced annually in the world. Coffea arabica (Arabica) and Coffea canephora var. robusta (Robusta) are the two main species of the genus Coffea that are cultivated for commercial production. Arabica is considered to be superior to Robusta because of its milder and more flavorful taste (Alonso-Salces et al., 2009). It accounts for $70-75 \%$ of the world production and is mainly used for the preparation of espresso coffee, whereas Robusta is mostly used for the manufacturing of instant coffee (Wintgens, 2009).

The production of coffee beverages or instant coffee leads to the generation a solid residue known as
Spent Coffee Grounds (SCG). SCG have no commercial value and are currently disposed of as a solid waste or, to a limited extent, used as fertilizers.

In recent years, the increasing demand for reducing the environmental impact of vegetable and food wastes has prompted the development of methods for their conversion into value-added products (Kosseva, 2009). The production of biofuels, such as ethanol and biodiesel (Singh et al., 2012), or the use as adsorbents for the removal of pollutants from wastewater (Lavecchia et al., 2010) are some of the proposed applications. Another promising, but still relatively unexplored, approach is the use of vegetable wastes as a raw material for the recovery of functional or healthpromoting compounds. Examples of this approach are the extraction of proanthocyanidins from grape seeds (Yilmaz et al., 2011) andthe recovery of Corresponding Author: Antonio Zuorro, Department of Chemical Engineering, Materials and Environment,
Faculty of Engineering, Sapienza University, Via Eudossiana 18, I-00184, Rome, Italy 
lycopene from tomato processing waste (Zuorro and Lavecchia, 2010a; Zuorro et al., 2011).

Coffee beans contain several classes of healthrelated chemicals, including phenolic compounds, melanoidins, diterpenes, xanthines and vitamin precursors (Mussatto et al., 2011). Caffeine is the most studied coffee component because of its psychoactive and medicinal properties (Crozier et al., 2012). Recently, however, coffee phenolics have attracted the greatest attention from the scientific and medical communities due to their strong antioxidant properties (Dai and Mumper, 2010). Their activity seems to be enhanced by the presenceof coffee melanoidins, which are thought to provide protection against free radical damage and reduce the risk of some degenerative diseases (Moreira et al., 2012).

In a previous study (Zuorro and Lavecchia, 2012) we found that SCG collected from espresso machines or coffee capsules had a high content of total phenolics (about $20 \mathrm{mg}$ GAE/g dry weight) and could be easily recovered by an aqueous extraction procedure. Chemical characterization of the extracts showed that chlorogenic acids and related compounds, particularly dichlorogenic acids and quinolactones, were the most abundant phenolic compounds (Panusa et al., 2013). In view of these findings, the present study was undertaken to systematically investigate the influence of the main process parameters (solvent composition, temperature, extraction time and liquid-to-solid ratio) on the recovery of phenolic compounds. In addition, we were interested in understanding whether and how the extraction conditions could affect the antioxidant activity of the resulting extracts.

\section{MATERIALS AND METHODS}

\subsection{Chemicals}

Ethanol, hydrochloric acid, sodium acetate, sodium carbonate and aluminum chloride were purchased from Carlo Erba (Milano, Italy). Gallic acid (3,4,5trihydroxybenzoic acid), DPPH (2,2-diphenyl-1 picrylhydrazyl) and the Folin-Ciocalteu's phenol reagent were obtained from Sigma-Aldrich Co. (St. Louis, Mo, USA). All chemicals were of analytical grade, with purities greater than $99 \%$ and used without further purification.

\subsection{Spent Coffee Grounds}

SCG were collected on different days from coffee bars in the city of Rome. To prevent microbial growth, they were dried to $7-10 \%$ residual moisture and pooled together. Drying was carried out at $40^{\circ} \mathrm{C}$ for $12-15 \mathrm{~h}$ in an electric forced-air food dehydrator (Stöckli, Switzerland). The dried material was put in glass bottles and stored in the dark at room temperature until use.

SCG were analysed for moisture, fiber, protein, fat, sugar, wax and ash content using standard analytical methods. Prior to performing extraction, the phenolic content of the waste was also evaluated.

\subsection{Analytical Methods}

Moisture content was determined by an electronic moisture analyzer (model MAC 50/1, Radwag, Poland). To evaluate the initial phenolic content of coffee waste, a three-stage extraction procedure allowing an almost complete exhaustion of the solid was used (Zuorro and Lavecchia, 2012). Briefly, $0.2 \mathrm{~g}$ of SCG and appropriate amounts of solvent $(20,10$ and $5 \mathrm{~mL}$ in and third stage, respectively) were poured into glass flasks thermostated at $60^{\circ} \mathrm{C}$ and stirred for $30 \mathrm{~min}$. After this time, the liquid was recovered, filtered at $0.45 \mu \mathrm{m}$ and assayed for total phenolics.

Total phenolics were determined by the Folin Ciocalteu's method. Five mL of $0.1 \mathrm{M} \mathrm{HCl}, 150 \mu \mathrm{L}$ of Folin-Ciocalteu's reagent and $200 \mu \mathrm{L}$ of the sample to be tested were poured into a graduated glass vial and an aqueous $\mathrm{Na}_{2} \mathrm{CO}_{3}$ solution $(20 \% \mathrm{w} / \mathrm{v})$ was added to a final volume of $10 \mathrm{~mL}$. The vial was thoroughly shaken and kept at room temperature in the dark for $1 \mathrm{~h}$. Then, the absorbance at $525 \mathrm{~nm}$ was measured with a colorimeter (HI83742, Hanna Instruments, Italy). The total phenolic content was expressed as gallic acid equivalents (mg GAE per $g$ of dry solid), using a calibration curve obtained with gallic acid standards.

Antioxidant activity was evaluated by the DPPH assay. A DPPH stock solution at $1 \mathrm{~g} \mathrm{~L}^{-1}$ in methanol was first prepared and stored at $-20^{\circ} \mathrm{C}$. Just before performing the assay, a working DPPH solution at $0.05 \mathrm{~g} \mathrm{~L}^{-1}$ was made by diluting the stock solution with methanol. Fifty to $300 \mu \mathrm{L}$ of the sample to be assayed were then poured into an optical glass cuvette and the working DPPH solution was added to a final volume of $4 \mathrm{~mL}$. After 30-min incubation at room temperature in the dark, the absorbance at $517 \mathrm{~nm}$ was measured. The antioxidant activity was expressed as $\mathrm{EC}_{50}$ value, which represents the concentration $(\% \mathrm{v} / \mathrm{v})$ of the sample in the cuvette necessary to decrease the initial DPPH concentration by $50 \%$. 


\subsection{Extraction Procedure}

Phenolic antioxidants were recovered from SCG by a batch extraction procedure using ethanol-water mixtures as extraction solvent. Appropriate amounts of SCG and the solvent were loaded into 50 or $100 \mathrm{~mL}$ screw-top pyrex flasks. The flasks were placed in a water bath thermostated at $\pm 0.1^{\circ} \mathrm{C}$ and were magnetically stirred. At the desired time, a sample of the liquid was taken, passed through a $45-\mu \mathrm{m}$ nylon filter and assayed for phenolic content and antioxidant activity.

A first series of experiments was performed to determine the optimal composition of the solvent mixture. They were carried out at $40^{\circ} \mathrm{C}$ with an extraction time of $105 \mathrm{~min}$ and a liquid-to-solid ratio of $30 \mathrm{~mL} \mathrm{~g}^{-1}$. The mixture giving the highest yield was then used to assess the influence of the main process variables on the recovery of phenolic antioxidants.

To evaluate the amount of dry phenolic extracts obtainable from SCG, a mechanically stirred extractor with a working volume of $1.5 \mathrm{~L}$ was used. In these experiments, $20 \mathrm{~g}$ of SCG were contacted with $1 \mathrm{~L}$ of solvent at $60^{\circ} \mathrm{C}$ for $3 \mathrm{~h}$. At the end of extraction, the solvent was evaporated in a Rotavapor R-215 (Büchi, Switzerland) and the solid residue analysed.

\subsection{Influential Factor Analysis}

A full-factorial design was used to evaluate the effects of the three main process parameters, Temperature (T), Extraction time (E) and liquid-to-solid Ratio (R), on the recovery of polyphenols from SCG. The levels of each factor were chosen so as to cover a range of values of practical interest (Table 1).

The test variables were coded to vary between -1 and +1 using the following Equations (1-3):

$\mathrm{x}_{1}=\frac{\mathrm{T}-40}{20}$

$\mathrm{x}_{2}=\frac{\mathrm{E}-105}{75}$

$\mathrm{x}_{3}=\frac{\mathrm{R}-30}{20}$

Four center-point $\left(x_{1}=x_{2}=x_{3}=0\right)$ replicates were also added, for a total of $2^{3}+4=12$ runs (Table 2). The extraction yield of phenolic compounds $(y)$ was used as the response variable. It was expressed as the percentage amount of extracted phenolics to the initial amount of phenolics in the waste.
Table 1. Factors and levels of the experimental design

\begin{tabular}{lllrr}
\hline & \multicolumn{3}{c}{ Level } \\
& Units & -1 & 0 & \multicolumn{1}{c}{+1} \\
\hline Factor & ${ }^{\circ} \mathrm{C}$ & 20 & 40 & 60 \\
Temperature (T) & $\mathrm{min}$ & 30 & 105 & 180 \\
Extraction time (E) & $\mathrm{mL} \mathrm{g}^{-1}$ & 10 & 30 & 50 \\
\hline Liquid-to-solid ratio (R) &
\end{tabular}

Table 2. Experimental design layout

\begin{tabular}{lrrrl}
\hline Std order & $\mathrm{x}_{1}$ & $\mathrm{x}_{2}$ & $\mathrm{x}_{3}$ & $\mathrm{y}$ \\
\hline 1 & -1 & -1 & -1 & 46.70 \\
2 & +1 & -1 & -1 & 62.89 \\
3 & -1 & +1 & -1 & 48.69 \\
4 & +1 & +1 & -1 & 64.65 \\
5 & -1 & -1 & +1 & 58.20 \\
6 & +1 & -1 & +1 & 86.53 \\
7 & -1 & +1 & +1 & 65.53 \\
8 & +1 & +1 & +1 & 90.35 \\
9 & 0 & 0 & 0 & 71.87 \\
10 & 0 & 0 & 0 & 72.39 \\
11 & 0 & 0 & 0 & 73.04 \\
12 & 0 & 0 & 0 & 74.45 \\
\hline
\end{tabular}

To minimize the effect of variability in the response due to extraneous factors, the experiments were performed in a random order.

The analysis of results was carried out using the

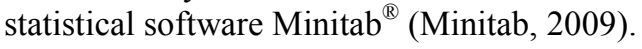

\section{RESULTS}

\subsection{Characterization of SCG}

The results of the physicochemical characterization of SCG are presented in Table 3. As can be seen, the waste contained significant amounts of fiber $(17.8 \%$, on a dry weight basis) and protein $(10.6 \%)$, while fats $(4.4 \%)$ and sugars $(<1 \%)$ were comparatively lower. Waxes and ash were in the range of values found for similar plant waste materials (Zuorro and Lavecchia, 2010b).

The initial moisture content of SCG was $48.2 \pm 2.2(\%$ $\mathrm{w} / \mathrm{w}$ ) and the total phenolic content, expressed as gallic acid equivalents per gram dry weight, was $18.75 \pm 0.43 \mathrm{mg} \mathrm{g}^{-1}$.

\subsection{Phenolic Extraction and Influential Factor Analysis}

Experiments aimed at determining the optimal composition of the ethanol-water mixture gave the results displayed in Fig. 1. The solvent composition had a strong influence on the extraction yield, which was maximum in mixtures containing $60 \%(\mathrm{v} / \mathrm{v})$ ethanol. We also found that the position of the maximum was not appreciably affected by the extraction temperature and the liquid-to-solid ratio. Accordingly, the 60:40 ethanol water mixture was used in all subsequent experiments. 


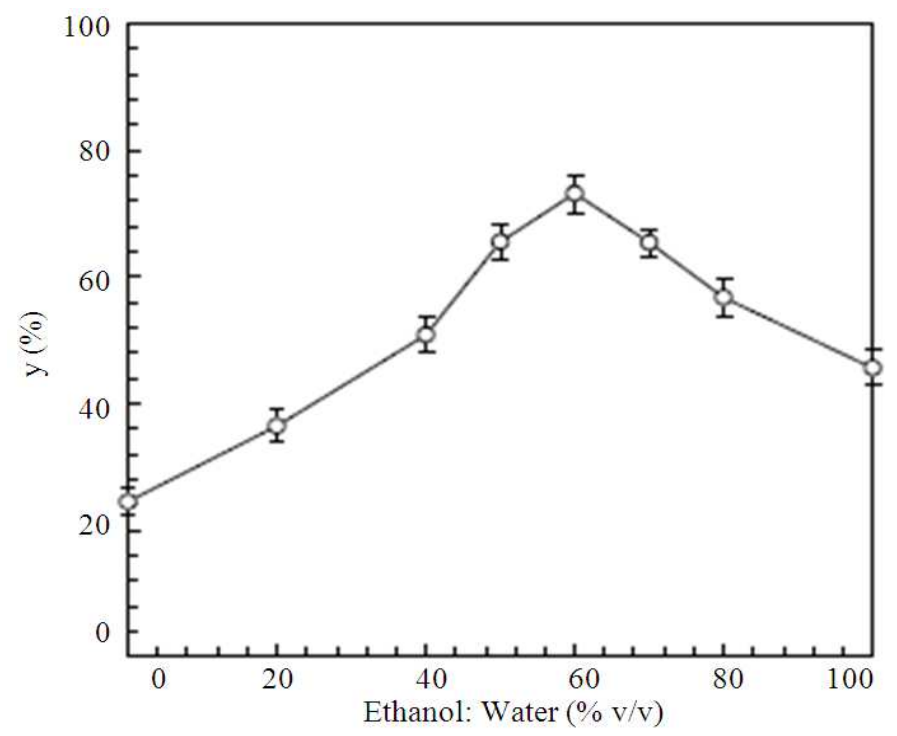

Fig. 1. Effect of solvent composition on the phenolic extraction yield $(y)$

Table 3. Physicochemical properties of SCG

\begin{tabular}{llll}
\hline Parameter & Method & Value & Unit \\
\hline Crude fiber & ISTISAN 96/34 68 & $17.8 \pm 0.8$ & $\% \mathrm{w} / \mathrm{w}$ \\
Protein & ISTISAN 96/34 13 & $10.7 \pm 0.4$ & $\% \mathrm{w} / \mathrm{w}$ \\
Fats & ISTISAN 96/34 39 & $4.4 \pm 0.2$ & $\% \mathrm{w} / \mathrm{w}$ \\
Sugars & ISTISAN 96/34 45 & $<1$ & $\% \mathrm{w} / \mathrm{w}$ \\
Total waxes & GU CE L161 2007 & $115 \pm 10$ & $\mathrm{mg} \mathrm{kg}^{-1}$ \\
Ash & ISTISAN 96/34 77 & $2.28 \pm 0.03$ & $\% \mathrm{w} / \mathrm{w}$ \\
Ash alkalinity & DM 03/02/89 II.14 & $293 \pm 10$ & $\mathrm{~mL} \mathrm{HCl}$ \\
\hline
\end{tabular}

The results of the experimental design are shown in Table 2. The extraction yields were between 46.7 and $90.35 \%$, corresponding to, respectively, 8.76 and 16.94 mg GAE per $g$ of dry SCG. The maximum yield was achieved at $60^{\circ} \mathrm{C}$ with an extraction time of $180 \mathrm{~min}$ and a liquid-to-solid ratio of $50 \mathrm{~mL} \mathrm{~g}^{-1}$.

To evaluate the contribution of the three main factors Temperature (T), Extraction time (E), liquid-to-solid Ratio (R) and their interactions to the extraction efficiency, the experimental data were correlated by the following Equation 4:

$$
\begin{aligned}
& y=\alpha_{0}+ \\
& \sum_{i=1}^{3} \alpha_{i} x_{i}+\sum_{i=1}^{3} \sum_{j=I+1}^{3} \alpha_{i j} x_{i} x_{j}+\alpha_{123} x_{1} x_{2} x_{3}
\end{aligned}
$$

where, $a_{i}$ are the coefficients associated with the main effects, $a_{i j}$ are those related to the binary interactions, $a_{123}$ is the quaternary interaction coefficient, $y$ is the response variable and the x's are the coded variables.
The polynomial model described by Equation 4 contains eight unknown coefficients, representing the contribution of each factor, alone or in combination, to the extraction yield. They were determined using the data of runs 1-8 in Table 2. Their values are summarized in Table 4. To assess the statistical significance of these coefficients we followed the procedure described in a previous paper (Zuorro et al., 2013). In particular, the standard deviation of the experimental response was first estimated from the central points of the factorial design (runs 9-12 in Table 2). Then, the $95 \%$ confidence interval of each coefficient was determined by the Student's t-test and the coefficients with confidence intervals not spanning zero were considered statistically significant $(p<0.05)$.

An examination of the results reported in Table 4 reveals that five out of the eight coefficients were statistically significant. In addition to the intercept, $\mathrm{a}_{0}$, they included the coefficients associated with the three main factors and the interaction between $T$ and $R$.

The positive sign of $T, R$ and $E$ indicates that they had a positive effect on the extraction yield, with $\mathrm{T}$ and $\mathrm{R}$ exerting a stronger influence. The value and sign of the interaction coefficient suggest that an increase in temperature has a more pronounced effect on the recovery of phenolics at higher liquid-to-solid ratios. These considerations are well illustrated by the Pareto chart in Fig. 2, where the significant coefficients are marked with an asterisk. 
Antonio Zuorro and Roberto Lavecchia / American Journal of Applied Sciences 10 (5): 478-486, 2013

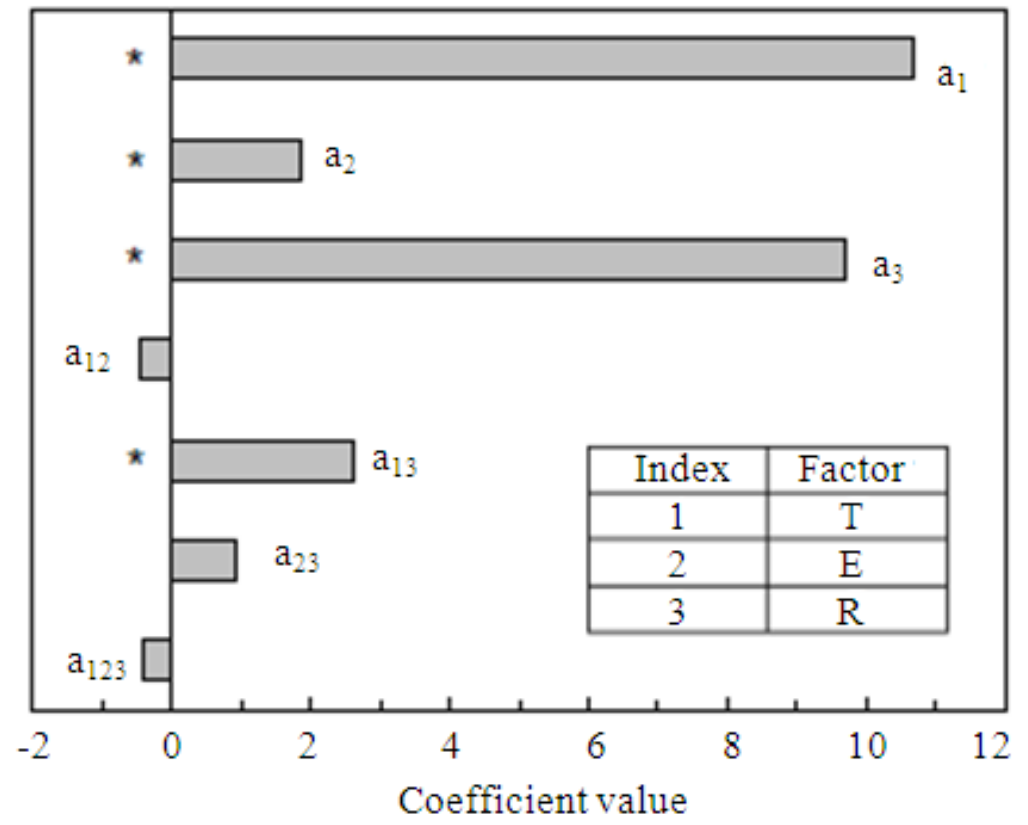

Fig. 2. Pareto chart showing the effects of the main factors and their interactions on the phenolic extraction yield. Significant coefficients are marked with an asterisk

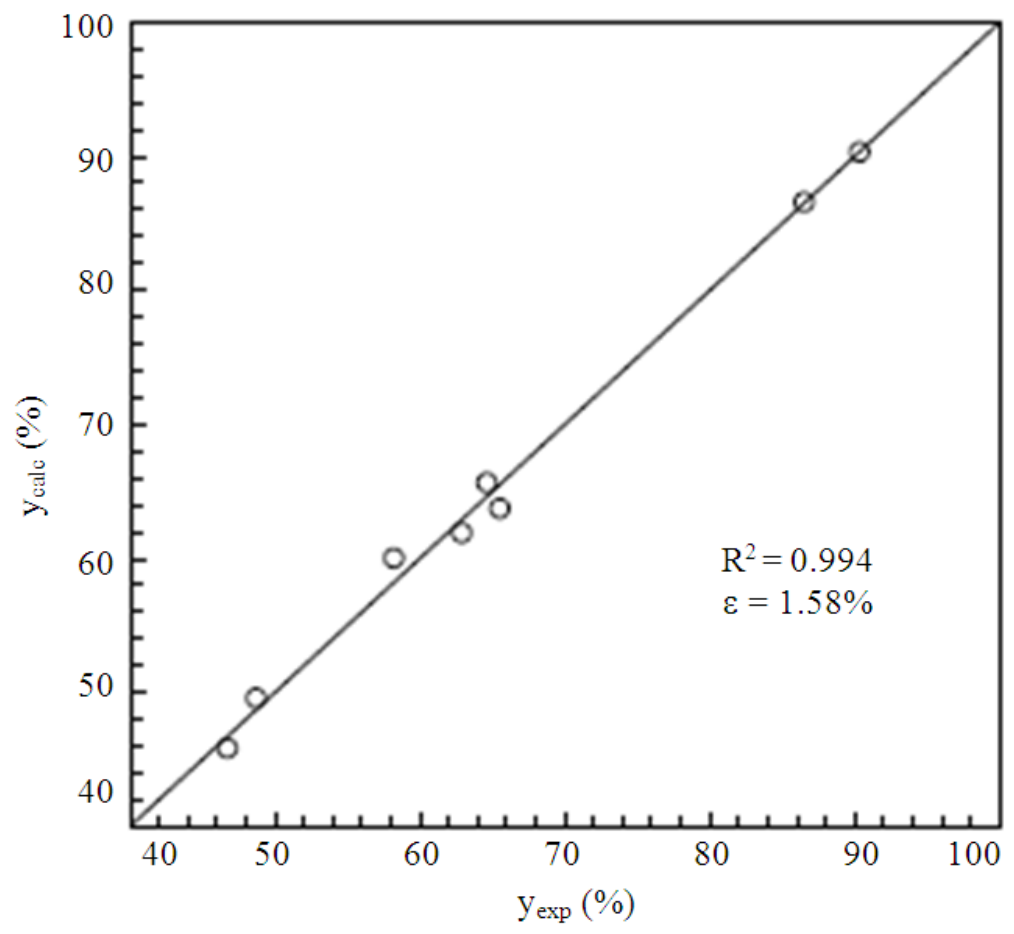

Fig. 3. Comparison between experimental and calculated (by Equation 5) extraction yields 


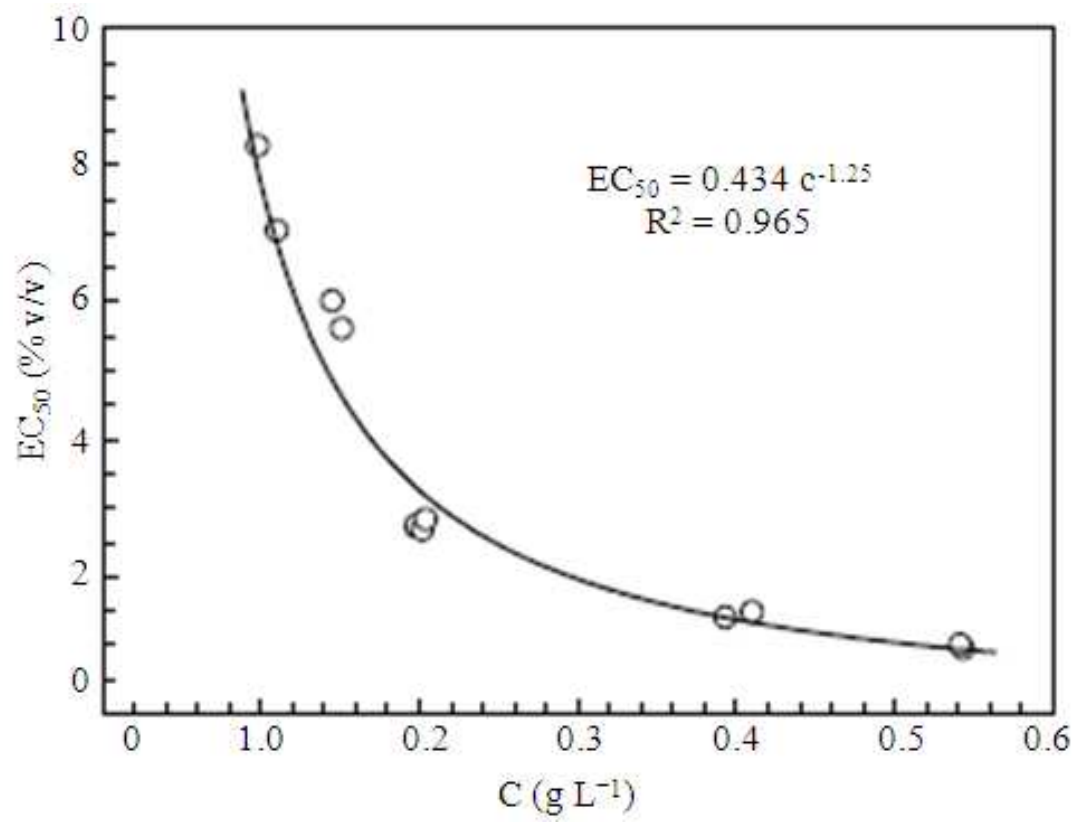

Fig. 4. Observed dependence of antioxidant activity, expressed as $\mathrm{EC}_{50}$ values, on the total phenolic content $(c)$ of the extracts

Table 4. Values and $t$-statistics for the coefficients in Equation 4. Significant values $(\mathrm{p}<0.05)$ are represented in bold

\begin{tabular}{llrr}
\hline Coefficient & Effect & Value & \multicolumn{1}{c}{$t$-value } \\
\hline$a_{0}$ & - & 65.443 & 165.835 \\
$a_{1}$ & $\mathrm{~T}$ & 10.663 & 27.019 \\
$a_{2}$ & $\mathrm{E}$ & 1.863 & 4.720 \\
$a_{3}$ & $\mathrm{R}$ & 9.710 & 24.606 \\
$a_{12}$ & $\mathrm{~T}-\mathrm{E}$ & -0.467 & 1.185 \\
$a_{13}$ & $\mathrm{~T}-\mathrm{R}$ & 2.625 & 6.652 \\
$a_{23}$ & $\mathrm{E}-\mathrm{R}$ & 0.925 & 2.344 \\
$a_{123}$ & T-E-R & -0.410 & 1.039 \\
\hline
\end{tabular}

By removing the non-significant terms from the full polynomial model, the following simplified expression was derived:

$\mathrm{y}=\mathrm{b}_{0}+\mathrm{b}_{1} \mathrm{x}_{1}+\mathrm{b}_{2} \mathrm{x}_{2}+\mathrm{b}_{3} \mathrm{x}_{3}+\mathrm{b}_{13} \mathrm{x}_{1} \mathrm{x}_{3}$

The five coefficients in Equation (5) were estimated from the experimental data by least-squares regression analysis. A very good agreement was found between experimental and calculated yields (Fig. 3), with an average error of $1.58 \%$.

Finally, from the experiments performed in the mechanically-stirred extractor we determined the amount of dry phenolic extract obtainable from SCG (A) and its phenolic titer (TI), expressed in terms of gallic acid equivalents. Their values were: $\mathrm{A}=173 \pm 10 \mathrm{mg} \mathrm{g}^{-1}$ (on a dry weight basis) and $\mathrm{TI}=15 \pm 2(\% \mathrm{w} / \mathrm{w})$.

\subsection{Antioxidant Activity of the Phenolic Extracts}

All the extracts obtained from SCG exhibited high antioxidant activity, with $\mathrm{EC}_{50}$ values ranging from 0.86 to $7.53(\% \mathrm{v} / \mathrm{v})$. It should be remembered that the lower the EC50, the higher the antioxidant activity.

Plotting the $\mathrm{EC}_{50}$ values of the extracts against the corresponding phenolic content (c) gave the results shown in Fig. 4. It can be seen that the two quantities were highly correlated, leading to the conclusion that phenolic compounds are the main responsible for theantioxidant activity of the extracts.

\section{DISCUSSION}

While the interest for the use of SCG as a source of health-promoting compounds has rapidly grown in the last few years, little attention has so far been given to the technological aspects of the recovery process (Mussatto et al., 2011; Zuorro and Lavecchia, 2012). In this study we have investigated the influence of the main process parameters (temperature, extraction time and liquidto-solid ratio) on the extraction of phenolic antioxidants from SCG using aqueous ethanol as the solvent. The waste 
was collected from coffee bars in the city of Rome and used without any special treatments except drying.

The first point to note is the high phenolic content of the SCG examined: $18.75 \mathrm{mg}$ GAE per gram dry weight. This value is in line with those reported in the few published studies on SCG (Ramalakshmi et al., 2009; Zuorro and Lavecchia, 2011; Murthy and Naidu, 2012; Bravo et al., 2013). A comparison with the values found for other agro-industrial wastes, such as grape pomace (Louli et al., 2004), carrot peel waste (Chantaro et al., 2008), kiwi and apple peel wastes (Wijngaard et al., 2009), shows that SCG have a higher amount of phenolic compounds. This provides further support to the idea of using SCG as a source of natural antioxidants.

As is evident from Fig. 1, the composition of the solvent had a marked effect on the extraction yield and the use of the 60:40 ethanol-water mixture gave better results compared to pure ethanol or pure water. Similar results were obtained in studies on the extraction of phenolics from different materials, such as peanut skins (Nepote et al., 2005), olive leaves (Mylonaki et al., 2008) and the byproducts of kiwifruit juicing (Sun-Waterhouse et al., 2009). One explanation may lie in the fact that phenolic compounds exhibit a wide range of solubilities in polar solvents and are often more soluble in solvents less polar than water (Liu et al., 2000). We can therefore assume that the 60:40 ethanol-water mixture allows higher amounts of phenolic compounds to be dissolved. Nevertheless, other solvent-related effects could also be involved, such as a weakening of the solute-matrix interactions or the improved swelling of the plant matrix (Lavecchia and Zuorro, 2008). Swelling results from the adsorption of solvent molecules on the hydroxyl and carboxyl groups of cellulose fibers. Following adsorption, the distances between the fibers increase, causing the expansion of the material and an increase of surface area. This favors solvent penetration and the release of soluble compounds into the liquid. It is known that swelling inducers are characterized by small molar volume, high hydrogen bonding capability and large basicity, as is the case of ethanol (El Seoud, 2009).

By varying the process conditions, significant changes were observed in both the extraction yield and the antioxidant activity of the extracts. The highest recovery $(\mathrm{y}=90.35 \%)$ was achieved at $\mathrm{T}=60^{\circ} \mathrm{C}, \mathrm{E}=$ $180 \mathrm{~min}$ and $\mathrm{R}=50 \mathrm{~mL} \mathrm{~g}$. Another point to be emphasized is the significant contribution of temperature and liquid-to-solid ratio to the extraction yield of phenolics. By contrast, the effect of extraction time was less pronounced. A possible explanation is that most of the phenolic compounds contained in SCG are extracted at short times, so that a prolonged extraction has only limited effect on their recovery. From a practical point of view, this means that the use of longer times to get a quantitative extraction is neither technically appropriate nor economically justified. The positive effects of temperature and liquid-to-solid ratio can be explained by considering that an increase in temperature favors the release of phenolic compounds from SCG and that higher liquid-to-solid ratios enhance the mass-transfer of the dissolved substances from the solid to the solvent (Cussler, 2009).

The simplified model described by Equation 5 accounts for all of the above-mentioned effects and can therefore be used for a preliminary assessment of the influence of process variables on the recovery of phenolics from SCG.

Plotting the $\mathrm{EC}_{50}$ values of the extracts against the corresponding phenolic content (c) gave the results shown in Fig. 4. It can be seen that the two quantities were highly correlated, leading to the conclusion that phenolic compounds are the main responsible for the antioxidant activity of the extracts.

\section{CONCLUSION}

This study demonstrates that phenolic-rich extracts can be obtained from SCG using a simple and environmentally friendly solvent-extraction procedure. The exploitation of SCG for these purposes would not only lead to the production of new products of potential interest to the cosmetic, pharmaceutical and food industries but also contribute to reducing the amount of coffee waste to be disposed of.

We have also shown that the recovery of phenolic compounds from SCG can be significantly improved by proper selection of extraction conditions. In this regard, the influential factor analysis we performed provides useful directions for future research and practical applications.

\section{REFERENCES}

Alonso-Salces, R.M., F. Serra, F. Remero and K. Heberger, 2009. Botanical and geographical characterization of green coffee (Coffea arabica and Coffea canephora): Chemometric evaluation of phenolic and methylxanthine contents. J. Agric. Food Chem., 57: 4224-4235. DOI: $10.1021 /$ jf8037117 
Bravo, J., C. Monente, I. Juaniz and M. Paz De Pena, 2013. Influence of extraction process on antioxidant capacity of spent coffee. Food Res. Int., 50: 610616. DOI: $10.1016 /$ j.foodres 2011.04.026

Chantaro, P., S. Devahastin and N. Chiewchan, 2008. Production of antioxidant high dietary fiber powder from carrot peels. LWT-Food Sci. Technol., 41: 1987-1994. DOI: 10.1016/j.lwt.2007.11.013

Crozier, T.W.M., A. Stalmach, M.E.J. Lean and A. Crozier, 2012. Espresso coffees, caffeine and chlorogenic acid intake: Potential health implications. Food Funct., 3: 30-33. DOI: $10.1039 / \mathrm{c} 1$ fo $10240 \mathrm{k}$

Cussler, E.L., 2009. Diffusion: Mass Transfer in Fuid Systems. 3rd Edn, Cambridge University Press,Cambridge, ISBN-10: 0521871212, pp: 631.

Dai, J. and R.J. Mumper, 2010. Plant phenolics: Extraction, analysis and their antioxidant and anticancer properties. Molecules, 15: 7313-7352. DOI: 10.3390/molecules 15107313

El Seoud, O.A., 2009. Understanding solvation. Pure Appl. Chem., 81: 697-707. DOI: 10.1351/PACCON-08-09-27

ICO, 2012. Total Coffee Production of Exporting Countries, London (UK). www.ico.org/trade_statistics.asp

Kosseva, M.R, 2009. Processing of food wastes. Adv. Food Nutr. Res., 58: 57-136. DOI: 10.1016/S10434526(09)58003-5

Lavecchia, R. and A. Zuorro, 2008. Improved lycopene extraction from tomato peels by cell-wall degrading enzymes. Eur. Food Res. Technol., 228: 153-158. DOI: $10.1007 / \mathrm{s} 00217-008-0897-8$

Lavecchia, R., A. Pugliese and A. Zuorro, 2010. Removal of lead from aqueous solutions by spent tea leaves. Chem. Eng. Trans., 19: 73-78. DOI: 10.3303/CET1019013

Liu, F.F., C.Y.W. Ang and D. Springer, 2000. Optimization of extraction conditions for active components in Hypericum perforatum using response surface meth-odology. J. Agric. Food Chem., 48: 33643371. DOI: $10.1021 / \mathrm{jf} 991086 \mathrm{~m}$

Louli, V., N. Ragoussis and K. Magoulas, 2004. Recovery of phenolic antioxidants from wine industry by-products. Bioresour. Technol., 92: 201208. DOI: 10.1016/j.biortech.2003.06.002

Minitab, 2009. Minitab reference manual (version 15.1.0.0), Minitab Inc. State College, PA, USA.
Moreira, A., F.M. Nunes, M.R. Domingues and M.A. Coimbra, 2012. Coffee melanoidins: Structures, mechanisms of formation and potential health impacts. Food Funct., 3: 903-915. DOI: $10.1039 / \mathrm{c} 2 \mathrm{fo} 30048 \mathrm{f}$

Murthy, P.S. and M.M. Naidu, 2012. Recovery of phenolic antioxidants and functional compounds from coffee industry by-products. Food Bioprocess Technol., 5: 897-903. DOI: 10.1007/s11947-0100363-z

Mussatto, S.I., L.M. Carneiro, J.P.A. Silva, I.C. Roberto and J.A. Teixeira, 2011. A study on chemical constit-uents and sugars extraction from spent coffee grounds. Carbohyd. Polym., 83: 368-374. DOI: 10.1016/j.carbpol.2010.07.063

Mylonaki, S., E. Kiassos, D.P. Makris and P. Kefalas, 2008. Optimisation of the extraction of olive (Olea europaea) leaf phenolics using water/ethanol-based solvent. Anal. Bioanal. Chem., 392: 977-985. DOI: 10.1007/s00216-008-2353-9

Nepote, V., N. Grosso and C. Guzman, 2005. Optimization of extraction of phenolic antioxidants from peanut skins. J. Sci. Food Agric., 85: 33-38. DOI: $10.1002 /$ jsfa. 1933

Panusa, A., A. Zuorro, R. Lavecchia, G. Marrosu and R. Petrucci, 2013. Recovery of natural antioxidants from spent coffee grounds. J. Agric. Food. Chem., 61: 4162-4168. DOI: 10.1021/jf4005719

Ramalakshmi, K., L. Jagan Mohan Rao, Y. TakanoIshikawa and M. Goto, 2009. Bioactivities of lowgrade green coffee and spent coffee in different in vitro model systems. Food Chem., 115: 79-85. DOI: 0.1016/j.foodchem.2008.11.063

Singh, A., A. Kuila, S. Adak, M. Bishai and R. Banerje, 2012. Utilization of vegetable wastes for bioenergy generation. Agric. Res., 1: 213-222.

Sun-Waterhouse, D., I. Wen, R. Wibisono, L.D. Melton and S. Wadhwa, 2009. Evaluation of the extraction efficiency for polyphenol extracts from by-products of green kiwifruit juicing. Int. J. Food Sci. Technol., 44: 2644-2652. DOI: 10.1111/j.13652621.2009.02097.x

Wijngaard, H.H., C. Roble and N. Brunton, 2009. A survey of Irish fruit and vegetable waste and byproducts as a source of polyphenolic antioxidants. Food Chem., 116: 202-207. DOI: 10.1016/j.foodchem.2009.02.033

Wintgens, J.N., 2009. Coffee: Growing, Processing, Sustainable Production, 2nd Edn., Wiley, Weinheim, ISBN-10: 3527322868, pp: 1040. 
Yilmaz, E.E., E.B. Ozvural and H. Vural, 2011. Extraction and identification of proanthocyanidins from grape seed (Vitis vinifera) using supercritical carbon dioxide. J. Supercrit. Fluids, 55: 924-928. DOI: 10.1016/j.supflu.2010.10.046

Zuorro, A. and R. Lavecchia, 2010a. Mild enzymatic method for the extraction of lycopene from tomato paste. Biotechnol. Biotechnol. Equip., 24: 18541857. DOI: 10.2478/V10133-010-0028-0

Zuorro, A. and R. Lavecchia, 2010b. Adsorption of $\mathrm{Pb}$ (II) on spent leaves of green and black tea. Am. J. Applied Sci., 7: 153-159.

Zuorro, A. and R. Lavecchia, 2011. Polyphenols and energy recovery from spent coffee grounds. Chem. Eng. Trans., 25: 285-290. DOI: 10.3303/CET1125048
Zuorro, A. and R. Lavecchia, 2012. Spent coffee grounds as a valuable source of phenolic compounds and bioenergy. J. Clean. Prod., 34: 49-56. DOI: 10.1016/j.jclepro.2011.12.003

Zuorro, A., M. Fidaleo and R. Lavecchia, 2011. Enzymeassisted extraction of lycopene from tomato processing waste. Enzyme Microb. Technol., 49: 567573. DOI: 10.1016/j.enzmictec.2011.04.020

Zuorro, A., M. Fidaleo and R. Lavecchia, 2013. Response surface methodology (RSM) analysis of photodegradation of sulfonated diazo dye Reactive Green 19 by $\mathrm{UV} / \mathrm{H}_{2} \mathrm{O}_{2}$ process. J. Environ. Manage., 128: 28-35. DOI: 10.1016/j.jenvman.2013.04.023 